\title{
ACADÊMICOS DE MEDICINA FRENTE A UMA INSTITUIÇÃO DE APOIO À CRIANÇA COM CÂNCER PEDIÁTRICO: UM RELATO DE EXPERIÊNCIA
}

\author{
Suzyanne Pereira Taveira ${ }^{1}$, Larissa Raquel Siqueira Pinto ${ }^{1}$,Cicera Livia Vieira Martins ${ }^{1}$ \\ ,Denise Teixeira Lima², Bruna Raquel Gomes de Oliveira ${ }^{2}$, Elisangela Vilar de Assis ${ }^{3}$
}

Introdução: O câncer pediátrico insere-se nas patologias neoplásicas que acometem a faixa etária entre zero e 19 anos. A abordagem das neoplasias na infância e na adolescência tem como enfoque o diagnóstico precoce e o acompanhamento multidisciplinar. Nesse contexto, notou-se a importância dos primeiros contatos dos acadêmicos de medicina com instituições dirigidas a esse público. Objetivo: Discorrer acerca da experiência de discentes de Medicina com pacientes oncológicos pediátricos em uma Organização Não Governamental (ONG). Método: O relato de experiência consistiu na realização de duas visitas ao Instituto de Apoio a Criança com Câncer (IACC), localizado no município de Barbalha-CE. O embasamento teórico foi feito por meio de uma pesquisa na base de dados Scielo, utilizando os descritores: "Oncologia" e "Pediatria"; "Experiência" e "Oncologia", ambos com a expressão booleana AND. Resultados: Durante a visita, observaram-se aspectos fundamentais no funcionamento da ONG, atualmente acolhendo 56 crianças da macrorregião de saúde do Cariri, tais como infraestrutura, corpo de colaboradores e projetos de apoio psicossocial à criança com câncer e seus responsáveis. Notaram-se deficiências em relação ao sistema de busca ativa dos pacientes, pois não há um treinamento efetivo dos profissionais de saúde com enfoque no diagnóstico precoce e há falha de interligação entre os setores que compõem o serviço de saúde e o IACC. Contudo, o vínculo criado e a preocupação em melhorar o serviço por parte dos profissionais do instituto são essenciais para o bem-estar dos pacientes e de seus familiares. Analisar o paradoxo vivido pela criança no contexto da infância e do estar doente colabora para a formação médica futura, uma vez que a falta de preparo ao lidar com essa situação de possibilidade de perda é um fator limitante para a atuação profissional. Conclusão: As visitas acrescentam à formação profissional um exercer futuro mais humanístico, fortalecendo a relação médico-paciente. Por meio de projetos extracurriculares, voluntariado e uma imersão no cotidiano dessas ONGs por parte dos estudantes, é possível uma melhoria não somente para os usuários dessas, mas para a sociedade como um todo. Logo, debruçar-se sobre isso durante o período universitário é crucial.

Palavras chave: Experiência. Oncologia. Pediatria.

\footnotetext{
${ }^{1}$ Acadêmica do Curso de Medicina da Faculdade de Medicina Estácio de Juazeiro do Norte - Juazeiro do Norte-CE;

${ }^{2}$ Acadêmica do Curso de Medicina da Faculdade Santa Maria - Cajazeiras-PB;

${ }^{3}$ Fisioterapeuta. Doutora em Ciências da Saúde pela Faculdade de Medicina do ABC, Santo André, São Paulo. Docente da Faculdade Santa Maria - FSM - Cajazeiras-PB;

Autor correspondente: suzyannep.taveira@gmail.com.
} 